\title{
The Bipolar II-Borderline Personality connection: treatment implications and prevention of relapses Giulio Perugi*
}

Address: Istituto di Scienze del Comportamento G De Lisio, Clinica Psichiatrica Universitá di Pisa, Italy

* Corresponding author

from International Society on Brain and Behaviour: 2nd International Congress on Brain and Behaviour Thessaloniki, Greece. 17-20 November 2005

Published: 28 February 2006

Annals of General Psychiatry 2006, 5(Suppl I):S54 doi:I0.II86/I744-859X-5-SI-S54

Many patients within the Bipolar II spectrum, especially when recurrence is high and the inter-episodic period is not free of affective manifestations, may meet criteria for personality disorders. This is particularly true for cyclothymic bipolar II patients, who are often misclassified as borderline personality disorder because of their extreme mood instability and reactivity. In patients with cyclothymic temperament and bipolar II disorders, lifetime comorbidity with anxiety disorders, in particular panic disorder- agoraphobia, bulimia nervosa, body dysmorphic disorder, alcohol and substance abuse disorder and both cluster $C$ (anxious) and cluster B (dramatic) personality disorders, is the rule rather than the exception (Perugi and Akiskal, 2002). In particular, a large proportion of these patients meet DSM-IV criteria for borderline personality disorders. Cyclothymic-bipolar II-borderline patients display a long-lasting "stable" hyper-reactivity to many psychological (i.e, rejection, separation) and physical (i.e., food, light, drugs) stimuli. This marked reactivity of mood could also explain the frequent concomitance of impulse control disorder and substances and alcohol abuse. An analysis of the explanatory power of affective temperaments and personality disorders for each of the criteria of BPD (Perugi et al., in press) revealed that the presence of cyclothymic temperament explains much of the relationship between bipolar II disorder and BPD. The diagnosis of BPD in these patients was favored by the coexistence of an affective cyclothymic temperamental dysregulation coexisting with anxious-dependent traits. We find no reason to separate bipolar II with cyclothymic instability from the stable instability of the borderline type, because mood lability is a common characteristic of both sets of disorders. Further, correlational analyses (Perugi et al., 2003) indicate that in bipolar II atypical depressives mood reactivity and interpersonal sensitivity traits might be related constructs with a cyclothymic temperamental matrix.

The enlargement of classical bipolar II disorders to include a spectrum of conditions subsumed by a cyclothymic-anxious-sensitive disposition, with mood reactivity and interpersonal sensitivity, and ranging from mood, anxiety and impulse control disorders, will greatly enhance both clinical practice and research endeavors Conceptualizing these patients to be related with a common diathesis, in our view will make them more understandable in the language of affective processes - and thereby make them accessible to pharmacological and psychological approaches geared to their shared temperamental attributes.

Treatment of BPD is complex and challenging and numerous studies using different psychotropic agents in BPD have been published. Among the pharmacological agents, Lithium has not been well studied, while anticonvulsants such as Valproate and Lamotrigine have demonstrated modest efficacy in acute and long-term treatment of BPD. Recently, low dosage of atypical antipsychotics has been shown to be well- tolerated and effective for the acute treatment of BPD. We have conducted an open label naturalistic study in order to evaluate the long-term effectiveness and the tolerability of an add-on treatment with atypical antipsychotics (Olanzapine, Risperidone and Quetiapine) in 48 patients with bipolar disorder with comorbid BPD. All patients were resistant or partially responders to the ongoing treatment with mood stabilizers. The mean (sd) duration of the observation was 43.6 (29.8) weeks (range 4-72); 17 patients received risperidone (35.4\%), 20 olanzapine (41.7\%), and 11 quetiapine (22.9\%). $28(58.3 \%)$ patients resulted as responders according to the final score of the CGI-Improvement scale 
( 1 or 2 ) (9 risperidone, 13 olanzapine and 6 quetiapine). Olanzapine and quetiapine were better tolerated in terms of extrapiramidal side effects but were associated with a greater weight gain in comparison with risperidone. After 24 weeks of treatment patients who responded to Olanzapine tend to show a more stable response and a lower rate of relapse when compared with those treated with risperidone. This finding suggest a mood stabilizing effectiveness of Olanzapine in long term treatment of bipolar patients with comorbid BPD. This preliminary observations should be confirmed in randomized controlled studies.

\section{References}

I. Perugi G, Akiskal HS: The soft bipolar spectrum redefined: focus on the cyclothymic-anxious-sensitive, impulse-dyscontrol, and binge-eating connection in bipolar II and related conditions. Psychiatr Clin North Am 2002, 25:713-737.

2. Perugi G, Toni C, Travierso MC, Akiskal HS: The role of Cyclothymia in Atypical Depression: Toward a data-based reconceptualization of the Borderline-Bipolar II connection. J Affect Disord 2003, 73:87-98.

3. Perugi G, Akiskal HS: Are Bipolar II, Atypical Depression, and Borderline Personality overlapping manifestations of a common cyclothymic-sensitive diathesis? J Clin Psychiatry 2005 in press.

Publish with Biomed Central and every scientist can read your work free of charge

"BioMed Central will be the most significant development for disseminating the results of biomedical research in our lifetime. "

Sir Paul Nurse, Cancer Research UK

Your research papers will be:

- available free of charge to the entire biomedical community

- peer reviewed and published immediately upon acceptance

- cited in PubMed and archived on PubMed Central

- yours - you keep the copyright

Submit your manuscript here:

http://www.biomedcentral.com/info/publishing_adv.asp 